\title{
Primipara Mothers who delivered vaginally or by cesarean section, is there an impact on the sexual function?
}

\author{
${ }^{1}$ Mohamed M. Al-Sherbiny, ${ }^{1}$ Rehab M. Abdelrahman, ${ }^{1}$ Amr A. Riad, \\ ${ }^{2}$ Ahmed M. Adel Abdelgawad, ${ }^{1}$ Mahmoud M. Elsayed \\ ${ }^{1}$ Department of Obstetrics and Gynecology, ${ }^{2}$ Department of Psychiatry Faculty of Medicine, Ain Shams University
}

Corresponding author: Mahmoud M. Elsayed; Mobile: 01004992772 Email: Rehababdulrhman.rm@gmail.com

\begin{abstract}
Background: The strength of the muscles of the pelvic floor and other supporting structures of the pelvic organs are affected by various events that occur during a woman's lifetime. Pregnancy and childbirth have a pronounced influence on maternal anatomy and physiology. Aim of the Work: The aim of the study was to investigate the impact of the mode of delivery on the sexual function (arousal-pleasure-orgasm-desire) among a representative sample of Egyptian primiparae. Subjects and Methods: This cross-sectional observational comparative study was conducted at Ain Shams University Maternity Hospital during the period between November 2017 and July 2018 on 260 women who had single uncomplicated delivery within a duration of not less than 6 months and not more than 2 years from recruitment of the study. Results: Pain was significantly positively correlated to the age $[\mathrm{r}=0.319, \mathrm{p}=0.013]$ and social class $[\mathrm{r}=0.276, \mathrm{p}=0.028]$. Both satisfaction and the overall sexual function score was also significantly positively correlated to social class $[\mathrm{r}=0.275, \mathrm{p}=0.032 ; \mathrm{r}=0.237, \mathrm{p}=0.048$; respectively]. Pelvic floor muscle strength was poorly correlated to sexual function. Conclusions: The study revealed a significant difference in pelvic floor muscle strength between women who delivered vaginally and those who delivered by Cesarean section. However, there was no significant difference in sexual function between women who delivered vaginally and those who delivered by Cesarean section. Pelvic floor muscle strength was poorly correlated to sexual function. Recommendations: Cesarean section on demand should not be considered as prophylaxis against sexual dysfunction. A larger, nation-wide based study should be performed for assessment of sexual dysfunction among women of different age groups and parities.
\end{abstract}

Key words: primipara, vaginal delivery, cesarean section, sexual function

\section{INTRODUCTION}

At the beginning of twenty-first century, efforts were exerted to continue acting on behalf the health and the safety of both the mother and the child, taking into consideration the mother's desire and preference and child's rights. This motion raised the concept of prophylactic cesarean delivery or as it sometimes referred as cesarean on patient's demand ${ }^{(\mathbf{1})}$.

During the first 3 months postpartum, many women experience some problems related to sexual function, such as dyspareunia, decreased libido, difficulty achieving orgasm, or vaginal dryness ${ }^{(2)}$.

Typically, these problems resolve by the end of first postpartum year. There are three mechanisms which may contribute to sexual dysfunction after childbirth: dyspareunia, birth canal injury ("pudendal neuropathy"), and overall general health of the mother ${ }^{(2)}$.

Thus, various obstetrical events such as cesarean, instrumental or spontaneous delivery or episiotomy could theoretically affect maternal sexual function in a dissimilar way. However, it is unclear whether or how these different obstetrical events influence short- or long-term prognosis for maternal sexual function ${ }^{(2)}$.

Sexual function was reported to be similar among women who delivered vaginally or by cesarean at 6 weeks ${ }^{(3)}$, or at 3 months ${ }^{(4)}$ or at 6 months ${ }^{(5)}$ postpartum.

Additionally, there was no reported impact of planned mode of delivery (vaginal vs. cesarean) on satisfaction with sexual relations at 2 years postpartum ${ }^{(6)}$.

At 6 weeks postpartum, women who had delivered vaginally without an episiotomy were reported to resume sexual activity sooner than those with an episiotomy ${ }^{(3)}$.

At 6 months postpartum, women who sustained anal sphincter lacerations were reported less likely to return to sexual activity ${ }^{(5)}$.

In a wider perspective, postpartum health will be considered in the following time period: immediate postpartum (birth to 6 months), short- 
term (3 to 6 months), and long-term (>6 months) (7).

According to different studies, perineal morbidity, postpartum sexual problems, and other complaints are related to the method of delivery. Sexual problems are associated more with instrumental birth and episiotomy than caesarean section $(\mathrm{C} / \mathrm{S})$ or normal vaginal delivery (NVD) (8).

Patient satisfaction with the birth process and quality of life postpartum are important factors to consider when determining the mode of delivery. Exploring the hypothesis that "sexual function" is associated with mode of delivery is important, because sexual health is an integral part of general health ${ }^{(9)}$. However, support for or against cesarean delivery on maternal request for the aforementioned outcomes and others is based on weak quality data, necessitating further research ${ }^{(\mathbf{1 0})}$.

\section{AIM OF THE WORK}

The aim of the study was to investigate the impact of the mode of delivery on the sexual function (arousal-pleasure-orgasm-desire) -among a representative sample of Egyptian primiparae.

\section{SUBJECTS AND METHODS}

The presented study was a cross sectional observational study included women attending the Ain-shams University Maternity Hospital outpatient gynecology or contraception clinics. The study was approved by the Ethics Board of Ain Shams University and an informed written consent was taken from each participant in the study.

Inclusion Criteria: The study included women who delivered only once. The delivery was more than 6 months ago but no longer than 2 years with age: $20-35$ years old, body mass index: 20-30, only women who delivered vaginally with a mediolateral episiotomy were included in the vaginal delivery group (as mediolateral episiotomy was almost a routine in our institute); only women who were delivered by a pre-labor cesarean section were included in the cesarean section group.

Exclusion criteria: Women who refused or were shy to answer questions about their sexual life, previous uterine surgery (apart from the cesarean section in the cesarean section group), women who were delivered by instrumental delivery, women who underwent intra-partum cesarean section and women with husbands discovered to have any illness or disease affecting their sexual function.

Consent: The purpose and the methods of the study were explained to and consent was obtained from all participating women. All women were assured about the privacy of their data.

Study design: Women attending the gynecology or contraception clinic at Ain Shams maternity hospital were invited to participate in this study according to the inclusion and exclusion criteria. All the women were informed about its content, value and privacy and only those consenting to participate were enrolled in the study. The study population was divided into 2 groups: those who underwent vaginal delivery with mediolateral episiotomy and those who underwent pre-labor cesarean section.

All women were questioned and examined by the female investigator in a suitable private setting. Demographic and social variables such as their educational level, current marital status, frequency of sexual activity, and socioeconomic status (determined by residence, income, occupation and educational level) were obtained. All women were questioned and examined vaginally for the presence of cystocele, rectocele, uterine descent, perineal laceration and/or symptoms of stress incontinence and fecal incontinence. Participants were placed in the dorsal lithotomy position with a full bladder and asked to strain as though attempting defecation. They were also asked to cough. If a cystocele, rectocele, or uterine descent is present, it was noted. If a participant has a history of urine loss with coughing or the examiner observes urine loss with coughing during the examination, the diagnosis of stress incontinence was made. The perineal laceration assessment was also made by vaginal and rectal examination.

Pelvic floor muscle strength was assessed using vaginal palpation (Manual muscle testing). The modified Oxford Grading System to measure Pelvic floor muscle strength introduced by Laycock $^{(11)}$, was adopted. This is a 6-point scale: $0=$ no contraction, $1=$ flicker, $2=$ weak, $3=$ =moderate, $4=$ good (with lift), and 5=strong. This measurement scale is commonly used because it can be incorporated with vaginal palpation in the same clinical assessment. It is simple to use and it does not require expensive equipment nor previous experience $^{(\mathbf{1 1})}$.

The sexual function was assessed using the Female Sexual Function Index (FSFI) 
questionnaire. The FSFI is a validated 19-item self-report measure of female sexual function that provides scores on 6 domains using factor analysis. The FSFI, a 19-item questionnaire, has been developed as a brief, multidimensional selfreport instrument for assessing the key dimensions of sexual function in women. It is psychometrically sound, easy to administer, and has demonstrated ability to discriminate between clinical and nonclinical populations. The FSFI was designed and validated for assessment of female sexual function and quality of life in clinical trials or epidemiological studies ${ }^{(\mathbf{1 2})}$. It was translated and explained to the participants. both groups

Primary outcome: FSFI scores among

Ethical committee approval: The study was conducted after gaining the approval of the ethical committee of the Ain-shams University Maternity Hospital.

Sample size justification: Sample size was calculated using EpiInfo ${ }^{\circledR}$ version 6.0, setting the type- 1 error $(\alpha)$ at 0.05 and the power $(1-\beta)$ at 0.80 . Data from a previous study, showed that the mean of FSFI score in CS and NVD (23.6 \pm 6.45 versus $22.45 \pm 5.85$ ) respectively, the difference 1.15 , with p-value $>0.05$ non-significant, Calculation according to these values produced a minimal sample size of 257 women, assuming a drop-out ratio of $5 \%$, the sample size will be 270 women.

\section{Statistical analysis:}

Data were collected and coded, tabulated, and statistically analyzed using SPSS program (Statistical Package for Social Sciences) software version 17.0.

Descriptive statistics were done for numerical parametric data as mean \pm SD (standard deviation) and minimum \& maximum of the range and for numerical non parametric data as median and $1^{\text {st }} \& 3^{\text {rd }}$ inter-quartile range, while they were done for categorical data as number and percentage.

Inferential analyses were done for quantitative variables using independent t-test, in cases of two independent groups, with parametric data.

Inferential analyses were done for qualitative data using Chi square test for independent groups. The level of significance was taken at: P-value $<0.05$ is significant, $\mathrm{p}$-value $<0.01$ highly significant and $p$-value $>0.05$ non significant.

\section{Female Sexual Function Index (FSFI) questionnaire $^{(12)}$}

Sexual desire or interest is a feeling that includes wanting to have a sexual experience, feeling receptive to a partner's sexual initiation, and thinking or fantasizing about having sex.

\section{FSFI Domain Scores And Full Scale Score ${ }^{(12)}$}

\section{RESULTS}

Table (1): Comparison between women who delivered vaginally and women who delivered by cesarean section concerning demographic data.

\begin{tabular}{|c|c|c|c|c|}
\hline & $\begin{array}{l}\text { Group I } \\
\text { [Vaginal } \\
\text { Delivery] } \\
(\mathbf{n}=130) \\
\end{array}$ & \begin{tabular}{|c|} 
Group II \\
[Cesarean \\
Section] \\
$(\mathbf{n}=130)$ \\
\end{tabular} & $t / x 2 \#$ & $\begin{array}{c}p- \\
\text { value }\end{array}$ \\
\hline $\begin{array}{l}\text { Age (Years) } \\
\text { Range: } \\
\text { Mean } \pm \text { SD: }\end{array}$ & $\begin{array}{c}20-29 \\
24.28 \pm 2.77\end{array}$ & $\begin{array}{c}20-30 \\
25.11 \pm 2.97\end{array}$ & 0.491 & 0.221 \\
\hline $\begin{array}{l}\text { BMI }\left(\mathbf{K g} / \mathbf{m}^{2}\right) \\
\text { Range: } \\
\text { Mean } \pm \text { SD: } \\
\end{array}$ & $\begin{array}{c}21.19-28.41 \\
26.39 \pm 1.77\end{array}$ & \begin{tabular}{|c|}
$21.94-$ \\
29.07 \\
$26.55 \pm 1.80$ \\
\end{tabular} & 0.784 & 0.196 \\
\hline $\begin{array}{l}\text { Social Class [No. } \\
(\boldsymbol{\%})] \\
\text { Low social class: } \\
\text { Middle social class: } \\
\end{array}$ & $\begin{array}{l}95(73.1 \%) \\
35(26.9 \%)\end{array}$ & $\left|\begin{array}{l}70(53.8 \%) \\
60(46.2 \%)\end{array}\right|$ & 2.611\# & 0.671 \\
\hline $\begin{array}{l}\text { Birth Weight }(\mathbf{K g}) \\
\text { Range: } \\
\text { Mean } \pm \text { SD: }\end{array}$ & $\begin{array}{c}2.8-4 \\
3.41 \pm 0.30\end{array}$ & $\begin{array}{c}2.5-4.5 \\
3.45 \pm 0.53\end{array}$ & 1.061 & 0.196 \\
\hline \begin{tabular}{l|} 
Delivery-to- \\
Recruitment \\
Interval (months) \\
Range: \\
Mean \pm SD:
\end{tabular} & $\begin{array}{c}6-24 \\
14.11 \pm 5.24\end{array}$ & $\begin{array}{c}6-24 \\
14.19 \pm 5.60\end{array}$ & 0.746 & 0.201 \\
\hline
\end{tabular}

Analysis using independent student's t-test

\# Analysis using Fischer's Exact test

NS non-significant

Of the included 260 women, only 15 (5.8\%) reported symptoms of stress urinary incontinence; in all of them it was evident by pelvic examination. Pelvic examination also revealed presence of cystocele in 15 (5.8\%) women, rectocele in $15(5.8 \%)$ women, firstdegree uterine prolapse in $3(1.2 \%)$ woman and combined cystocele and first-degree uterine descent in 3 (1.2\%) woman (table 6).

Table (2): Comparison between women who delivered vaginally and women who delivered by Cesarean section concerning stress urinary incontinence and uterovaginal prolapse.

\begin{tabular}{|l|c|c|c|c|}
\hline & $\begin{array}{c}\text { Group I } \\
{[\text { Vaginal }} \\
\text { Delivery] } \\
(\mathbf{n}=\mathbf{1 3 0})\end{array}$ & $\begin{array}{c}\text { Group II } \\
\text { [Cesarean } \\
\text { Section] } \\
(\mathbf{n}=\mathbf{1 3 0})\end{array}$ & $\boldsymbol{x} 2$ & $\begin{array}{c}\boldsymbol{p} \text { - } \\
\text { value }\end{array}$ \\
\hline $\begin{array}{l}\text { Evident Stress Urinary } \\
\text { Incontinence (by } \\
\text { symptoms and pelvic }\end{array}$ & $9(6.9 \%)$ & $0(0 \%)$ & 6.291 & $\begin{array}{c}0.014 \\
\mathrm{~S}\end{array}$ \\
\hline
\end{tabular}




\begin{tabular}{|l|c|c|c|c|}
\hline examination) & & & & \\
\hline Utero-vaginal Prolapse & & & & \\
No Prolapse: & 110 & $130(\%)$ & & \\
Cystocele: & $(84.6 \%)$ & $0(0 \%)$ & & \\
Rectocele: & $7(5.4 \%)$ & $0(0 \%)$ & 12.481 & 0.006 \\
First-Degree Uterine & $7(5.4 \%)$ & $0(0 \%)$ & & $\mathrm{S}$ \\
Descent: & $3(2.3 \%)$ & & & \\
$\begin{array}{l}\text { Combined Cystocele } \\
\text { and First-Degree }\end{array}$ & $3(2.3 \%)$ & $0(0 \%)$ & & \\
Uterine Descent & & & & \\
\hline
\end{tabular}

Data expressed as number (percentage)

* Analysis using Fischer's Exact test

** Analysis using Chi-squared test

Significant

Pelvic floor muscle strength was assessed in all included women by manual palpation, and was graded according to the Modified Oxford Grading System to measure pelvic floor muscle strength ${ }^{(\mathbf{1 3})}$. Of the included 260 women, $6(2.3 \%)$ had weak pelvic floor muscles, $17(6.54 \%)$ had moderate pelvic floor muscles, 69 (26.54\%) had good pelvic floor muscles, and 168 (64.62\%) had strong pelvic floor muscles (table 3 ).

Table (3): Comparison between women who delivered vaginally and women who delivered by cesarean section concerning pelvic floor muscle strength.

\begin{tabular}{|c|c|c|c|c|}
\hline & $\begin{array}{c}\text { Group I } \\
\text { [Vaginal } \\
\text { Delivery] } \\
(n=130)\end{array}$ & \begin{tabular}{|c|} 
Group II \\
[Cesarean \\
Section] \\
$(\mathrm{n}=130)$
\end{tabular} & $x 2$ & p-value \\
\hline $\begin{array}{l}\text { Pelvic Floor Muscle } \\
\text { Strength* } \\
\text { Grade } 0 \text { (no } \\
\text { contraction) } \\
\text { Grade } 1 \text { (Flicker) } \\
\text { Grade } 2 \text { (Weak) } \\
\text { Grade } 3 \text { (moderate) } \\
\text { Grade } 4 \text { (good, with } \\
\text { lift) } \\
\text { Grade } 5 \text { (strong) }\end{array}$ & $\begin{array}{c}0(0 \%) \\
0(0 \%) \\
6(4.6 \%) \\
17 \\
(13.1 \%) \\
55 \\
(42.3 \%) \\
52 \\
(40.0 \%)\end{array}$ & $\begin{array}{c}0(0 \%) \\
0(0 \%) \\
0(0 \%) \\
0(0 \%) \\
14 \\
(10.8 \%) \\
116 \\
(89.2 \%)\end{array}$ & 17.496 & $\begin{array}{c}<0.001 * * \\
\text { HS }\end{array}$ \\
\hline
\end{tabular}

* Based on The Modified Oxford Grading System to measure Pelvic Floor Muscle Strength (18).

Data expressed as number (percentage)

Analysis using Chi-squared test

HS highly significant

Sexual function was assessed using the Female Sexual Function Index (FSFI) questionnaire. The mean desire score in all included women was $6.64 \pm 1.77$ (range: 2-10). The mean arousal score in all included women was 14.74 \pm 3.81 (range: 0-20). The mean lubrication score in all included women was
$16.59 \pm 4.42$ (range: $0-20$ ). The mean orgasm score in all included women was $12.52 \pm 2.98$ (range: 0 15). The mean satisfaction score in all included women was $12.59 \pm 3.15$ (range: $2-15$ ). The mean pain score in all included women was $13.40 \pm 2.71$ (range: $0-15$ ). The mean overall sexual score in all included women was $28.78 \pm 5.33$ (range: 5-36) (Table 4).

Table (4): Comparison between Women who delivered vaginally and women who delivered by Cesarean section concerning sexual function*

\begin{tabular}{|c|c|c|c|c|}
\hline & $\begin{array}{c}\text { Group I } \\
\text { [Vaginal } \\
\text { Delivery] } \\
(\mathbf{n}=\mathbf{4 5}) \\
\end{array}$ & $\begin{array}{c}\text { Group II } \\
\text { [Cesarean } \\
\text { Section] } \\
(\mathbf{n}=45) \\
\end{array}$ & $t$-test & $\begin{array}{c}p- \\
\text { value }\end{array}$ \\
\hline $\begin{array}{l}\text { Desire Score } \\
\text { Range: } \\
\text { Mean } \pm \text { SD: }\end{array}$ & $\begin{array}{c}3-9 \\
6.36 \pm 1.32\end{array}$ & $\begin{array}{c}2-10 \\
6.29 \pm 2.01\end{array}$ & 0.380 & 0.156 \\
\hline $\begin{array}{l}\text { Arousal Score } \\
\text { Range: } \\
\text { Mean } \pm \text { SD: }\end{array}$ & $\begin{array}{c}0-20 \\
13.89 \pm 3.61\end{array}$ & $\begin{array}{c}8-20 \\
14.2 \pm 3.68\end{array}$ & 0.802 & 0.329 \\
\hline $\begin{array}{l}\text { Lubrication } \\
\text { Score } \\
\text { Range: } \\
\text { Mean } \pm \text { SD: }\end{array}$ & $\begin{array}{c}0-20 \\
16.53 \pm 3.62\end{array}$ & $\begin{array}{c}0-20 \\
15.07 \pm 4.66\end{array}$ & 0.213 & 0.087 \\
\hline $\begin{array}{l}\text { Orgasm Score } \\
\text { Range: } \\
\text { Mean } \pm \text { SD: }\end{array}$ & $\begin{array}{c}0-15 \\
11.82 \pm 2.99\end{array}$ & $\begin{array}{c}6-15 \\
12.02 \pm 2.72\end{array}$ & 0.841 & 0.345 \\
\hline $\begin{array}{l}\text { Satisfaction } \\
\text { Score } \\
\text { Range: } \\
\text { Mean } \pm \text { SD: }\end{array}$ & $\begin{array}{c}2-15 \\
11.91 \pm 3.22\end{array}$ & $\begin{array}{c}6-15 \\
12.07 \pm 2.81\end{array}$ & 0.203 & 0.083 \\
\hline $\begin{array}{l}\text { Pain Score } \\
\text { Range: } \\
\text { Mean } \pm \text { SD: }\end{array}$ & $\begin{array}{c}0-15 \\
12.24 \pm 2.89\end{array}$ & $\begin{array}{c}6-15 \\
13.27 \pm 2.13\end{array}$ & 0.224 & 0.092 \\
\hline $\begin{array}{l}\text { Overall Sexual } \\
\text { Function } \\
\text { Score } \\
\text { Range: } \\
\text { Mean } \pm \text { SD: }\end{array}$ & $\begin{array}{c}5-32.9 \\
27.33 \pm 5.16\end{array}$ & $\begin{array}{c}18.3-36 \\
27.5 \pm 5.06\end{array}$ & 0.401 & 0.164 \\
\hline
\end{tabular}

* Based on Female Sexual Function Index (FSFI) (12)

** Analysis using independent student's t-test NS non-significant

Table (5) shows correlation between sexual function and other measured variables. Pain was significantly positively correlated to the age $[\mathrm{r}=0.319, \mathrm{p}=0.013]$ and social class $[\mathrm{r}=0.276$, $\mathrm{p}=0.028]$. Both satisfaction and the overall sexual function score was also significantly positively correlated to social class $[\mathrm{r}=0.275, \quad \mathrm{p}=0.032$; $\mathrm{r}=0.237, \mathrm{p}=0.048$; respectively]. Pelvic floor muscle strength was poorly correlated to sexual function. 
Table (5): Correlation between Sexual Function and Each of Age, Mode of Delivery, BMI, Social Class, Birth Weight and Pelvic Floor Muscle Strength.

\begin{tabular}{|c|c|c|c|c|c|c|c|c|}
\hline & & Desire & Arousal & Lubrication & Orgasm & Satisfaction & Pain & Total Score \\
\hline \multirow{3}{*}{ Age } & & 0.079 & 0.187 & 0.067 & 0.217 & 0.176 & 0.319 & 0.228 \\
\hline & $r_{n}^{*}$ & $>0.05$ & $>0.05$ & $>0.05$ & $>0.05$ & $>0.05$ & 0.013 & $>0.05$ \\
\hline & & NS & NS & NS & NS & NS & $\mathrm{S}$ & NS \\
\hline \multirow{3}{*}{$\begin{array}{l}\text { Mode of } \\
\text { Delivery }\end{array}$} & & -0.005 & 0.037 & -0.138 & 0.049 & 0.002 & 0.199 & 0.014 \\
\hline & $r^{r+6}$ & $>0.05$ & $>0.05$ & $>0.05$ & $>0.05$ & $>0.05$ & $>0.05$ & $>0.05$ \\
\hline & $p$ & NS & NS & NS & NS & NS & NS & NS \\
\hline \multirow{3}{*}{ BMI } & & -0.040 & 0.086 & 0.086 & 0.110 & 0.033 & -0.014 & 0.062 \\
\hline & $m_{n}^{r+2}$ & $>0.05$ & $>0.05$ & $>0.05$ & $>0.05$ & $>0.05$ & $>0.05$ & $>0.05$ \\
\hline & & NS & NS & NS & NS & NS & NS & NS \\
\hline \multirow{3}{*}{ Social Class } & & 0.070 & 0.109 & 0.095 & 0.200 & 0.276 & 0.275 & 0.237 \\
\hline & $r^{*}$ & $>0.05$ & $>0.05$ & $>0.05$ & $>0.05$ & 0.028 & 0.032 & 0.048 \\
\hline & $p$ & NS & NS & NS & NS & $\mathrm{S}$ & $\mathrm{S}$ & $\mathrm{S}$ \\
\hline \multirow{3}{*}{ Birth Weight } & & 0.122 & -0.061 & 0.056 & 0.014 & -0.037 & -0.214 & -0.001 \\
\hline & $a_{n}^{r}$ & $>0.05$ & $>0.05$ & $>0.05$ & $>0.05$ & $>0.05$ & $>0.05$ & $>0.05$ \\
\hline & & NS & $\mathrm{NS}$ & NS & NS & NS & NS & NS \\
\hline \multirow{3}{*}{$\begin{array}{l}\text { Pelvic floor } \\
\text { muscle } \\
\text { Strength }\end{array}$} & & 0.091 & 0.094 & -0.148 & -0.029 & 0.139 & 0.194 & 0.083 \\
\hline & $\left.\right|_{n} ^{r+n}$ & $>0.05$ & $>0.05$ & $>0.05$ & $>0.05$ & $>0.05$ & $>0.05$ & $>0.05$ \\
\hline & & NS & NS & NS & NS & NS & NS & NS \\
\hline
\end{tabular}

* Pearson's correlation coefficient

** Spearman's correlation coefficient

NS non-significant - $\mathrm{S}$ significant

\section{DISCUSSION}

The strength of pelvic floor muscles is decreased after childbirth, and vaginal delivery is accepted as the major cause of pelvic floor damage by many authors ${ }^{(14)}$.

Many women experience perineal discomfort or pain after childbirth, which can persist, often impairing sexual function. It is believed that vaginal birth, in particular operative delivery, negatively affects pelvic organ support and sexual functioning in women ${ }^{(15)}$.

The factors associated with a postpartum decrease of sexual function are breast-feeding, vaginal delivery, operative vaginal delivery, perineal trauma, vaginal tears, and episiotomy ${ }^{(\mathbf{1 6})}$.

Studies reported that sexual dysfunction occurs postnatally but performance returns to prepregnancy levels within 1 year after delivery (17)

Nowadays, some women prefer a cesarean delivery to avoid pelvic floor damage and possible impairment of sexual function and continence. As a consequence, the rates of cesarean delivery are increasing worldwide ${ }^{(\mathbf{1 8})}$.
Although pelvic floor damage and postpartum impairment of sexual function have been attributed to vaginal birth ${ }^{(\mathbf{1 9})}$, the extent to which the mode of delivery contributes to sexual dysfunction is not clear, nor is the relationship between mode of delivery and pelvic muscle strength in the long term. Indeed, studies have mostly focused on acute sexual problems such as loss of lubrication, pain on orgasm, pain during sexual intercourse, and loss of sexual desire for up to 6 months after childbirth ${ }^{(17)}$.

The pelvic floor muscles participate in female sexual function and responsiveness. These muscles are responsible for the involuntary rhythmic contractions during orgasm. The levator ani muscles also modulate motor responses during orgasm as well as receptivity. It was suggested that hypotonic muscles could cause vaginal hypoesthesia and coital anorgasmia ${ }^{(\mathbf{1 5})}$.

This cross-sectional study was conducted on 260 women who attended the Ain Shams maternity hospital outpatient gynecology clinic and contraception clinic, aged 20-30 years with a single uncomplicated delivery, six months-2 years from recruitment. Although most of the previous 
studies have chosen six months-one year for follow up period, we insisted to extend this interval up to two years as our primary aim was to assess the long term residual effects of mode of delivery upon certain aspects. Two years was a reasonable period for all changes attributed to labor to settle down and hence, we compared the long lasting residual effects of the mode of delivery, not those factors related to short-term complications, e.g. dyspareunia due to episiotomy scar. They were asked and examined for symptoms and signs of pelvic organ prolapse (cystocele, rectocele, or uterine descent), fecal or urinary incontinence. Pelvic floor muscles were assessed using vaginal palpation (Manual muscle testing). The modified Oxford Grading System to measure Pelvic floor muscle strength introduced by Laycock $^{(13)}$ was adopted. The sexual function was assessed using the Female Sexual Function Index (FSFI) questionnaire.

All included women were divided, according to mode of delivery, into 2 groups: group I $(\mathrm{n}=130)$ including women who delivered vaginally, and group II $(\mathrm{n}=130)$ including women who delivered by Cesarean section, of them, 40 $(30.8 \%)$ were due to infertility and/or recurrent miscarriage, $11(8.5 \%)$ due to failed induction of labor, $24(18.5 \%)$ due to malpresentation, 18 (13.8\%) due to suspected macrosomia, 29 (22.3\%) due to pre-eclampsia/eclampsia and $8(6.2 \%)$ due to potential fetal compromise. The mean age of included women was 25.08 \pm 3.09 years (range: 20-30 years). The mean BMI was $26.47 \pm 1.77$ $\mathrm{Kg} / \mathrm{m}^{2}$ (range: $21.19-29.07 \mathrm{Kg} / \mathrm{m}^{2}$ ). Of the included 260 women, $165(63.5 \%)$ were of low social class, while $95(36.5 \%)$ were of middle social class. This ensured that the sample studied is homogenous and alleviates the effect of many confounding factors.

Although both study groups were homogenous in this attribute, a drawback is the failure to recruit women from higher social classes. This fact can be comprehended as we were handicapped by the necessity to perform this study in Ain Shams Maternity Hospital outpatient clinics.
A larger nationwide study, including women representing the whole spectrum of the society may yield more representative results.

In the present study, the mean birth weight for group I was $3.41 \pm 0.30 \mathrm{~kg}$, and for group II was $3.45 \pm 0.53 \mathrm{~kg}$ with no statistically significant difference. The mean deliveryrecruitment interval (months) in group I was14.11 \pm 5.24 , while in group II was $14.19 \pm 5.60$ with no statistical significant difference between both groups. The detailed demographic and baseline data for both groups showed no statistically significant difference and this alleviates the effects of many confounding factors.

The presented study showed evident stress urinary incontinence (SUI) by history and pelvic examination to be prevalent among 15 $(5.8 \%)$ of the vaginal delivery group and absent in the Cesarean delivery group compared to $9 \%$ in both groups in the study conducted by Baytur $\boldsymbol{e t}$ al. ${ }^{(20)}$, on 80 Turkish women, and $15.1 \% 6$ months after the first vaginal delivery in the study conducted by Sarasqueta and Diez-Itza ${ }^{(21)}$, on 369 women with a single vaginal delivery without any kind of urinary incontinence prior to pregnancy.

Rortveit et al. ${ }^{(22)}$ also reported higher risk for urinary incontinence in the group of women who delivered vaginally in their study compared with the group that had Cesarean deliveries. Glazener et al. ${ }^{(11)}$, showed that $13.5 \%$ of women included in their study had SUI 3 months after their first vaginal delivery, while Wesnes et al. ${ }^{(23)}$, published rates of around $14 \% 6$ months after the first vaginal delivery.

The current study showed the prevalence of genitourinary prolapse was $20(15.4 \%)$ in the vaginal delivery group and absent in the Cesarean delivery group. Cystocele was present in 7 (5.4\%), rectocele was present in 7 (5.4\%) first degree uterine descent was present in $3(2.3 \%)$ and combined cystocele and first degree uterine descent in 3 (2.3\%) of the vaginal delivery group with statistically significant difference between both groups. 
Baytur et al. ${ }^{(20)}$, reported the presence of cystocele in $25 \%$ of the vaginal delivery group and $14 \%$ of the Cesarean delivery group in their studied cases with significant statistical difference between both groups, rectocele was present in 6\% of vaginal delivery group and absent in the Cesarean delivery group, uterine descent was present in 3\% of the vaginal delivery group and absent in the Cesarean delivery group with no significant statistical difference between both groups.

Hendrix et al. (24) demonstrated the prevalence rates of each type of prolpse: uterine prolapse $14 \%$, cystocele $34 \%$, and rectocele $18 \%$ in a study conducted on 27000 multiparous women.

Studies of sisters have shown that genetic predisposition may be more important than other risk factors such as parity in the development of prolapse $^{(25)}$.

In this study Pelvic floor muscle strength was assessed in all included women by manual palpation, and was graded according to the Modified Oxford Grading System to measure Pelvic Floor Muscle Strength ${ }^{(\mathbf{1 3})}$. Although using EMG or perineometer would have seemed more objective, this simple office-based test was used, owing to its ease, reproducibility and lack of inconvenience.

Of the included 260 women, 6 (2.3\%) had weak pelvic floor muscles, $17(6.54 \%)$ had moderate pelvic floor muscles, 69 (26.54\%) had good pelvic floor muscles, and $168(64.62 \%)$ had strong pelvic floor muscles

Women who delivered vaginally had a significantly higher proportions of weak and moderate pelvic floor muscles [6/130 (4.6\%) vs. 0/130 (0\%); $17 / 130(13.1 \%)$ vs. 0/130 (0\%); respectively] and a significantly lower proportions of strong pelvic floor muscles [52/130 (40\%) vs. 116/130 (89.2\%), respectively], when compared to women who delivered by CS [p<0.001].

Samples et al. ${ }^{(26)}$ stated that pelvic floor muscle strength was not affected in women delivered by Cesarean section. Baytur et al. ${ }^{(20)}$, concluded that pelvic floor muscle strength was significantly lower in the vaginal delivery group compared with the Cesarean delivery group measured using a silicone sensor perineometer.

In our study Sexual function was assessed using the Female Sexual Function Index (FSFI) questionnaire which was used for its ease, reliability and reproducibility. The mean desire score in all included women was $6.64 \pm 1.77$ (range: 2 - 10), ranging from 3-9 with mean score $6.36 \pm 1.32$ in vaginal delivery group and 2-10 with mean score 6.29 \pm 2.01 in Cesarean section group with no statistically significant difference. There are limited studies that specifically evaluate hypoactive sexual desire disorder in the postpartum period. Postpartum loss of sexual desire was reported by Barrett et al. ${ }^{(27)}$, to occur in 53\% at 3 months and $37 \%$ at 6 months after birth, 32\% resumed intercourse within 6 weeks after delivery and the majority of respondants (89\%) had resumed intercourse within 6 months.

Oboro and Tabowei ${ }^{(28)}$, in a Nigerian study concluded that postpartum loss of sexual desire occurred in $61 \%$ and $26 \%$ at 6 weeks and 6 months respectively. Baytur et al. ${ }^{(20)}$ reported no statistically significant difference between both groups using FSFI questionnaire.

In the presented study, the mean arousal score in all included women was $14.74 \pm 3.81$ (range: $0-20$ ), with a mean score of 13.89 in the vaginal delivery group and 14.2 in the Cesarean delivery group with no statistical significance. Baytur et al. ${ }^{(20)}$, found no statistically significant difference in arousal between the vaginal delivery and the Cesarean delivery groups using the FSFI scoring system. Baksu et al. ${ }^{(29)}$, evaluated the effect of mode of delivery on postpartum arousal in a group of 248 primiparous Turkish women in which sexual arousal was negatively affected in the group who had mediolateral episiotomies when compared to the Cesarean section group 6 months postpartum.

In the current study, the mean lubrication score in all included women was $16.59 \pm 4.42$ 
(range: $0-20$ ), with a mean score 16.53 in the vaginal delivery group and mean score 15.07 in the Cesarean delivery group with no statistically significant difference. The mean orgasm score in all included women was12.52 \pm 2.98 (range: $0-$ 15) with a mean score 11.82 in the vaginal delivery group and 12.02 in the Cesarean delivery group with no statistically significant difference. The mean satisfaction score in all included women was $12.59 \pm 3.15$ (range: 2 - 15) with a mean score 11.91 in the vaginal delivery group and 12.07 in the Cesarean delivery group with no statistically significant difference. The mean pain score in all included women was $13.40 \pm 2.71$ (range: $0-15$ ) with mean score 12.24 in vaginal delivery group and 13.27 in the Cesarean delivery group with no statistically significant difference. The mean overall sexual score in all included women was $28.78 \pm 5.33$ (range: 5 - 36) with a mean score 27.33 in the vaginal delivery group and 27.5 in the Cesarean delivery group with no significant statistical difference between both groups.

Baytur et al. ${ }^{(20)}$ found that lubrication, orgasm, satisfaction, pain and FSFI scores were not significantly different among the groups, although the vaginal delivery group had a slightly poorer sexual function in all domains. Baksu et al. (29) found that postpartum sexual function outcomes (lubrication, orgasm, satisfaction and pain) were negatively affected in the group who had mediolateral episiotomies when compared to the Cesarean section group at 6 months postpartum. The differences could be attributed to different study populations, sample sizes and study designs.

In the current study,. Pain was significantly positively correlated to the age $[\mathrm{r}=0.319, \mathrm{p}=0.013]$ and social class $[\mathrm{r}=0.276$, $\mathrm{p}=0.028]$. Both satisfaction and the overall sexual function score was also significantly positively correlated to social class $[\mathrm{r}=0.275, \mathrm{p}=0.032$; $\mathrm{r}=0.237, \mathrm{p}=0.048$; respectively]. Pelvic floor muscle strength was poorly correlated to sexual function.
Baytur et al. ${ }^{(20)}$, found no significant correlation between sexual function and social class or pelvic floor muscle strength.

This study has some limitations. The study group was small, and women with findings such as cystocele, rectocele, uterine descent and SUI were very few. There was no control group of nulliparous women to assess sexual function and pelvic floor muscle strength. No information was available about the length of the second stage of labor and pushing time in the vaginal delivery group which could have an effect on postpartum pelvic floor muscle strength and sexual function. The pelvic floor muscle strength was assessed using the modified Oxford grading system which is rather subjective; the results would have been more reliable if more objective methods were used, such as a perineometer.

\section{CONCLUSIONS}

There was a significant difference in pelvic floor muscle strength between women who delivered vaginally and those who delivered by Cesarean section

There was no significant difference in sexual function between women who delivered vaginally and those who delivered by Cesarean section

Pelvic floor muscle strength was poorly correlated to sexual function.

\section{RECOMMENDATIONS}

Cesarean section on demand should not be considered as prophylaxis against sexual dysfunction.

A larger, nation-wide based study should be performed for assessment of sexual dysfunction among women of different age groups and parities.

\section{REFERENCES}

1. Handelzalts JE, Fisher S, Lurie $S$ et al. (2012): Personality, fear of childbirth and cesarean delivery on.Acta Obstet Gynecol Scand., 91: 16-21 
2. Handa VL (2006): Sexual function and childbirth. Semin Perinatol., 30: 253-256.

3. Woranitat W, Taneepanichskul S (2007): Sexual function during the postpartum period. J Med Assoc Thai., 90: 1744-1748.

4. Klein K, Worda C, Leipold H et al. (2009): Does the mode of delivery influence sexual function after childbirth? J Women Health, 18: $1227-1231$

5. Brubaker L, Handa VL, Bradley CS et al. (2008): Weber a; pelvic floor disorders network. Sexual function 6 months after first delivery. Obstet Gynecol., 111: 1040-1044.

6. Hannah ME, Whyte H, Hannah WJ et al. (2004): Term breech trial collaborative group. Maternal outcomes at 2 years after planned cesarean section versus planned vaginal birth for breech presentation at term: the international randomized term breech trial. Am J Obstet Gynecol., 191: 917-927

7. Thompson JF, Roberts CL, Currie M (2002): Prevalence ans persistence of health problems after childbirth: associations with parity and methods of birth. Birth, 29(2): $83-$ 94.

8. Williams A, Herronmarx S, Knib R (2007): The prevalence of enduring postnatal perineal morbidity and its relationship to type of birth and birth risk fators. J Clin Nurs., 16: 549-61.

9. Safarinejad MR, Kolahi AA, Hosseini $L$ (2009). The effect of the mode of delivery on the quality of life, sexual function, and sexual satisfaction in primiparous women and their husbands. J Sex Med., 6(6): 1645-67.

10. South MMT, Stinnett SS, Sanders DB (2009): Levator ani denervation and reinnervation 6 months after childbirth. Am J Obstet Gynecol., 200(5): 519e1-7.

11. Glazener CM (2005): Women's health after delivery. In: Henderson C and Bick D., eds, Perineal care: an international issue $\left(1^{\text {st }} \mathrm{ed}\right.$.) Quay Books. Divisions, Salisbury, pp.: 11 17.
12. Rosen R, Brown C, Heiman J (2000): The female sexual function index (FSFI): a multidimensional self-report instrument for the assessment of female sexual function. J. Sex. Marital ther., 26(2): $191-208$.

13. Laycock J (1994): Clinical evaluation of the pelvic floor. In: Schussler B, Laycock J, Norton P, Stanton SL, eds. Pelvic Floor Reeducation. London, United Kingdom: Springer-Verlag.

14. Baessler $K$ and Schuessler $B$ (2003): Childbirth-induced trauma to the urethral continence mechanism: review and recommendations. Urology, 62: 39-44

15. Berman JR, Berman LA, Kanaly KA (2003): Female sexual dysfunction: new perspectives on anatomy, physiology, evaluation and treatment. EAU Update Ser., 1: 166-177.

16. Waterstone M, Wolfe C, Hooper R (2003): Postnatal morbidity after childbirth and sever obstetric morbidity. BJOG., 110: 128-133.

17. Abraham S, Child A, Ferry J et al. (1990): Recovery after childbirth: a preliminary prospective study, Med J Aust., 152: 9-12.

18. Arias E, MacDorman MF, Strobino DM et al. (2003): Annual summary of vital statistics. Pediaterics, 112: 1215-1230.

19. Lydon-Rochelle MT, Holt VL, Martin DP (2001): Delivery method and self-reported postpartum general health status among primiparous women. Paediatr. Perinat. Epidermal., 15(3): 232 - 240.

20. Baytur YB, Deveci A, Uyar Y et al. (2005): Mode of delivery and pelvic floor muscle strength and sexual function after childbirth. Int. J. Gynecol. Obstet., 88: 276-280.

21. Sarasqueta $C$ and Diez-Itza I (2010): Stress urinary incontinence six months after first vaginal delivery. EUR. J. Obstet. Gynecol.Reprod. Biol., 150: 210-214

22. Rortveit G, Daltveit AK, Hannestad YS (2003): Norwegian EPINCOT Study. Urinary 
incontinence after vaginal delivery or cesarean Section. N Engl. J. Med., 348 (10): 900-907.

23. Wesness SL, Hunskaar S, Bo K (2009): The effect of urinary incontinence status during pregnancy and delivery mode on incontinence postpartum. A cohort study. BJOG., 116: 700707.

24. Hendrix SL, Clark A, Nygaard I (2002): Pelvic organ prolapse in the Women's Health Initiative: gravity and gravidity, Am J Obstet Gynecol., 186: 1160-1166

25. Buchsbaum G, Kerr L, Guzick D (2003): Pelvic relaxation in nulliparous postmenopausal women and their parous sisters, Neurourol Urodyn., 22: 509.
26. Samples JT, Dougherty MC, Abrams RM (1998): The dynamic characteristics of the circumvaginal muscles. J Obstet Gynecol Neonatal Nurs., 17 194-201.

\section{Barrett G, Pendry E, Peacok J, Manyonda} I (2000): Women's sexual health after childbirth. BJOG., 107(2): 186-195.

28. Oboro VO and Tabowei TO (2002): Sexual function after childbirth in Nigrian women. Int. J. Gynecol. Obstet., 78(3): 249 - 250.

29. Baksu B, Davas I, Agar E et al. (2007): The effect of mode of delivery on postpartum sexual functioning in primiparous women. Int. Urogynecol. J. Pelvic Floor Dysfunct., 18(4): $401-406$. 